\title{
Predictive factors for local recurrence and incomplete resection of early gastric cancer treated by endoscopic resection: A Western experience
}

\author{
Fábio Yuji Hondo $M D^{1}$, Fauze Maluf-Filho MD PhD ${ }^{1}$, Humberto Setsuo Kishi $M D^{2}$, Ricardo Sato Uemura MD",
} Luciano Okawa MD¹, Ivan Cecconello MD PhD³, Paulo Sakai MD PhD¹

\begin{abstract}
FY Hondo, F Maluf-Filho, HS Kishi, et al. Predictive factors for local recurrence and incomplete resection of early gastric cancer treated by endoscopic resection: A Western experience. Can J Gastroenterol 2009;23(5):357-363.
\end{abstract}

BACKGROUND: Early gastric cancer (EGC) is defined as adenocarcinoma limited to the mucosa or submucosa regardless of lymph node involvement. Local EGC recurrence rates have been described in up to $6 \%$ of cases.

OBJECTIVES: To evaluate predictive factors for incomplete resection and local recurrence of EGC treated by endoscopic mucosal resection (EMR) that was followed up for at least one year.

METHODS: From June 1994 to December 2005, 46 patients with EGC underwent EMR. Possible predictive factors for incomplete endoscopic resection and local recurrence were identified by medical chart analysis. Demographic, endoscopic and histopathological data were retrospectively evaluated. EMR was considered complete or incomplete. Patients from the complete resection group were divided into subgroups (with and without local EGC recurrence).

RESULTS: Complete resection was possible in 36 cases (76.6\%). Predictive factors for incomplete resection were tumour location $(\mathrm{P}=0.035)$, histological type $(\mathrm{P}=0.021)$, lesion size $(\mathrm{P}=0.022)$ and number of resected fragments $(\mathrm{P}=0.013)$. On multivariate analysis, undifferentiated histological type (OR $0.8 ; 95 \%$ CI 0.036 to 0.897 ) and number of resected fragments (OR 7.34; $95 \%$ CI 1.266 to 42.629 ) were independent predictive factors for incomplete resection. In the complete resection group, a larger lesion size was associated with a higher the number of resected fragments $(\mathrm{P}=0.018)$. Local recurrence occurred in nine cases $(25 \%)$. Use of the cap technique was the only predictive factor for local recurrence in five of seven cases $(71.4 \%)$ $(\mathrm{P}=0.006)$.

CONCLUSIONS: A larger lesion size was associated with a higher number of resected fragments. Undifferentiated adenocarcinoma and piecemeal resection were predictive factors for incomplete resection. Technique type was a predictive factor for local EGC recurrence.

Key Words: Gastric neoplasms; Gastrointestinal endoscopy methods; Local neoplasm recurrence; Risk factors; Treatment outcome

Carly gastric cancer (EGC) is defined as adenocarcinoma

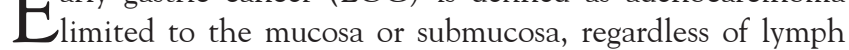
node involvement (1). In the West, EGC cases are diagnosed in approximately $7 \%$ to $15 \%$ of all cases of gastric adenocarcinoma (2). Gastric neoplasms with invasion depths restricted to the mucosal layer - without ulcers or scars - demonstrate the absence of lymph node involvement in the majority of cases (3). Consequently, treatment is enabled by endoscopic mucosal resection (EMR). The local recurrence rates of gastric adenocarcinomas after endoscopic resection ranges from $2 \%$ to $35 \%$

\author{
Facteurs prédictifs de la récurrence locale et de \\ la résection endoscopique incomplète du cancer \\ de l'estomac peu avancé : Expérience \\ occidentale
}

HISTORIQUE : Le cancer de l'estomac peu avancé se définit comme un adénocarcinome limité à la muqueuse ou à la sous-muqueuse, peu importe l'atteinte ganglionnaire. Des taux de récurrence locale du cancer de l'estomac peu avancé atteignant $6 \%$ ont été décrits.

OBJECTIF : Évaluer les facteurs prédictifs de résection incomplète et de récurrence locale du cancer de l'estomac peu avancé ayant été traité par résection muqueuse endoscopique (RME), après un suivi minimum d'une année.

MÉTHODE : De juin 1994 à décembre 2005, 46 patients présentant un cancer de l'estomac peu avancé ont subi une RME. Les facteurs prédictifs possibles de résection endoscopique incomplète et de récurrence locale ont été identifiés par analyse des dossiers médicaux. Les auteurs ont évalué de façon rétrospective les données démographiques, endoscopiques et histopathologiques. La RME a été jugée complète ou incomplète. Les patients du groupe ayant subi une résection complète ont été subdivisés encore (avec et sans récurrence locale du cancer de l'estomac).

RÉSULTATS : La résection complète a été possible dans 36 cas (76,6\%). Les facteurs prédictifs d'une résection incomplète étaient la localisation de la tumeur $(\mathrm{p}=0,035)$, le type histologique $(\mathrm{p}=0,021)$, la taille de la lésion $(\mathrm{p}=0,022)$ et le nombre de fragments réséqués $(\mathrm{p}=0,013)$. À l'analyse multivariée, le type histologique indifférencié (RC 0,8; IC à $95 \%, 0,036$ à 0,897 ) et le nombre de fragments réséqués ( $\mathrm{RC} 7,34$; IC à $95 \%, 1,266$ à 42,629) ont été des facteurs prédictifs indépendants de résection incomplète. Dans le groupe ayant subi la résection complète, la taille plus grande de la lésion a été associée à un nombre plus élevé de fragments réséqués $(\mathrm{p}=0,018)$. Une récurrence locale a été observée dans neuf cas (25\%). L'utilisation de la technique par capuchon a été le seul facteur prédictif de récurrence locale dans cinq cas sur sept $(71,4 \%)(p=0,006)$.

CONCLUSION : La taille de la lésion était proportionnelle au nombre de fragments reséqués. L'adénocarcinome indifférencié et la résection fragmentaire ont été des facteurs prédictifs d'une résection incomplète. Le type de technique a été un facteur prédictif de la récurrence locale du cancer de l'estomac au premier stade.

$(4,5)$, provided that indication criteria for mucosectomies are respected (3,6-10).

The objective of the present study was to evaluate predictive factors for incomplete resection and local recurrence of EGC treated by EMR that was followed-up for at least one year or until death.

Patients

METHODS

From June 1994 to December 2005, data from the medical charts of 53 patients with a diagnosis of EGC, who underwent

${ }^{1}$ Gastrointestinal Endoscopy Unit; ${ }^{2}$ Pathological Anatomy Department; ${ }^{3}$ Esophagus, Stomach and Small Intestine Surgery Unit, Sao Paulo

University Medical School, Sao Paulo, Brazil

Correspondence and reprints: Dr Fábio Yuji Hondo, Sao Paulo University Medical School, Rua Panamericana 64, Sao Paulo 04303-170, Brazil.

Telephone 55-115-587-5946, fax 55-113-069-7579, e-mail fyhondo@hotmail.com

Received for publication August 6, 2008. Accepted October 5, 2008 
endoscopic treatment with mucosectomy at the Sao Paulo University Medical School, Sao Paulo, Brazil, were reviewed. Inclusion criteria were diagnosis of EGC treated by EMR with follow-up for at least one year. Seven patients were excluded due to follow-up failure after endoscopic treatment.

Demographic (sex, age and race), endoscopic and histopathological data were collected and assessed through medical chart reviews and interviews with patients or the patients' relatives.

Macroscopic classifications established by the Japanese Research Society of Gastric Cancer (11) were used. Lesions were classified as type I (protruded type), type II (superficial type [subdivided into type IIa - elevated type]), type IIb (flat type), type IIc (depressed type), type III (excavated type) and mixed types (ie, IIa + IIc). The location of lesions (according to the Japanese Gastric Cancer Association [12]) was classified in the upper, middle and lower one-third of the stomach and, considering the gastric circumference, in the greater and lesser curvature anterior and posterior wall. The techniques used for resection were strip biopsy (lift and cut), cap (suck and cut) and endoscopic submucosal dissection (ESD). Lesions were grouped into en bloc resection (single fragment) and piecemeal resection (two or more fragments) categories, classified by size and divided into two subgroups (lesions up to $2 \mathrm{~cm}$ in size or larger than $2 \mathrm{~cm}$ in size).

Resected specimens were evaluated by two pathologists using the pathology classification defined by the World Health Organization in 1990 and divided into tubular or papillarytubular (Nakamura's well-differentiated or Lauren's intestinaltype carcinoma) and microtubular or signet-ring cell carcinoma (Nakamura's undifferentiated or Lauren's diffuse-type carcinoma). Regarding the level of invasion, lesions were classified as mucosal (M)1, M2 and M3, and submucosal (SM)1, SM2 and SM3.

\section{Follow-up}

Endoscopic mucosectomies were considered complete resections when lateral or deep margins were endoscopically and histopathologically clear of neoplasms. Otherwise, they were considered incomplete resections.

Patients with incomplete resections were referred to surgical treatment or complementary endoscopic treatment depending on their clinical conditions, histopathological type of cancer and their personal preference.

The patients with complete resections were submitted to endoscopic follow-up with quarterly scar biopsies during the first year, every six months past the second year, and annually thereafter. Patients who presented with local recurrence of cancer on control endoscopic examination were included in the recurrence group.

\section{Statistics}

Data were calculated as means \pm SD. The $\chi^{2}$ test was used for noncontinuous parameters. The Mann-Whitney test was used for numerical values. For the comparison of follow-up period for subgroups with and without recurrence, the Student's $t$ test was used. Statistical significance for the tests used in the present study was established at $\mathrm{P}<0.05$. Multivariate analysis through logistic regression tests were performed to calculate statistical differences across comparative parameters of groups or subgroups.

\section{RESULTS}

A total of 46 patients diagnosed with EGC underwent endoscopic resection and were followed up for at least one year. These 46 patients underwent a total of 47 EMR procedures between June 1994 and November 2004. Twenty-three patients $(50 \%)$ were women with mean age of $69 \pm 14.1$ years (range 21 to 102 years). Ten patients $(21.7 \%)$ were younger than 60 years of age and $36(78.2 \%)$ were 60 years of age or older. Thirty-four patients $(73.9 \%)$ were Caucasian, four were black $(8.7 \%)$ and eight patients (17.4\%) were Asian.

Regarding pathological diagnosis, well-differentiated adenocarcinoma was found in 27 cases $(59.5 \%)$ and undifferentiated adenocarcinoma in 20 cases (40.4\%). In total, 40 tumours $(72.3 \%)$ were less than $2 \mathrm{~cm}$ in size and $7(27.7 \%)$ were larger than $2 \mathrm{~cm}$. Mucosal involvement was verified in 34 cases $(72.3 \%)$, of which five $(10.6 \%)$ were classified as M1, 11 cases $(23.4 \%)$ as M2 and 18 cases $(38.3 \%)$ as M3. Submucosal invasion occurred in 13 cases $(27.7 \%)$, of which $10(21.3 \%)$ were classified as SM1 and three $(6.4 \%)$ were classified SM2.

On endoscopy, 47 gastric lesions were diagnosed and their macroscopic types were classified as type IIa in 31 cases (66\%), type IIc in seven (14.9\%) and type IIa+IIc in nine cases $(19.1 \%)$.

The location of the lesions was classified into the upper, middle and lower one-third of the stomach. When the lesions were defined through this classification, the predominant location of lesions was in the middle one-third (26 cases [55.3\%]).

The lesions were also classified by their location in the gastric circumference through the greater curvature, the lesser curvature, the anterior wall and the posterior wall. Under this classification, the predominant location of the lesion was in the greater curvature (20 cases $[42.5 \%]$ ).

A case-by-case analysis based on these two classifications, revealed the greater curvature of the middle one-third of the stomach as the predominant location of lesions (14 cases [29.8\%]). Endoscopic resection techniques included EMR (with cap) in seven cases (14.9\%), strip biopsy in 38 (80.9\%) and insulation-tipped diathermic (IT) knife in two (4.3\%).

Regarding the number of resection fragments, en bloc resections were performed in $24(51 \%)$ cases and piecemeal resections in the remaining 23 cases $(48.9 \%)$.

The correlation between the number of resected fragments and tumour size indicated that the larger the lesion, the higher the number of resected fragments and vice versa. There was no statistical difference in the comparison between the number of resected fragments and the technique used (Table 1). No statistcally significant difference was observed in the comparison between the mucosectomy technique and the location of the lesion ( $\mathrm{P}=0.650)$.

The mean follow-up period was $69.4 \pm 36$ months (range six to 136 months). A five-year survival rate of $58.3 \%$ after endoscopic treatment was verified. There were seven deaths (15.2\%); however, none were a result of gastric cancer. Of these cases, one patient presented evidence of adenocarcinoma by the time of evolution to death (Figure 1).

Patients were divided into complete and incomplete resection groups. There was no statistical difference in the demographic variables of sex, age or race between the incomplete and complete resection groups (Table 2). Mucosectomy with tumour-free margins were observed in 36 resections $(76.6 \%)$.

Cancer location was a predictive factor for incomplete tumour removal $(\mathrm{P}=0.035)$. For lesions located in the upper 
TABLE 1

Comparison of the number of resection fragments with mucosectomy technique and size of resected lesion

\begin{tabular}{lccc}
\hline & \multicolumn{2}{c}{ Number of fragments } & \\
\cline { 2 - 3 } & One & Two or more & P \\
\hline Technique & & & \\
$\quad$ Cap & $4(57.1)$ & $3(42.9)$ & 0.328 \\
Strip biopsy & $18(47.4)$ & $20(52.6)$ & \\
Insulation-tipped & $2(100)$ & 0 & \\
$\quad$ diathermic knife & & & \\
Size of resected lesion & & & \\
$\leq 2 \mathrm{~cm}$ & $21(61.8)$ & $13(38.2)$ & \\
$>2 \mathrm{~cm}$ & $3(23.1)$ & $10(76.9)$ & \\
\hline
\end{tabular}

Data presented as $n$ (\%) unless indicated otherwise

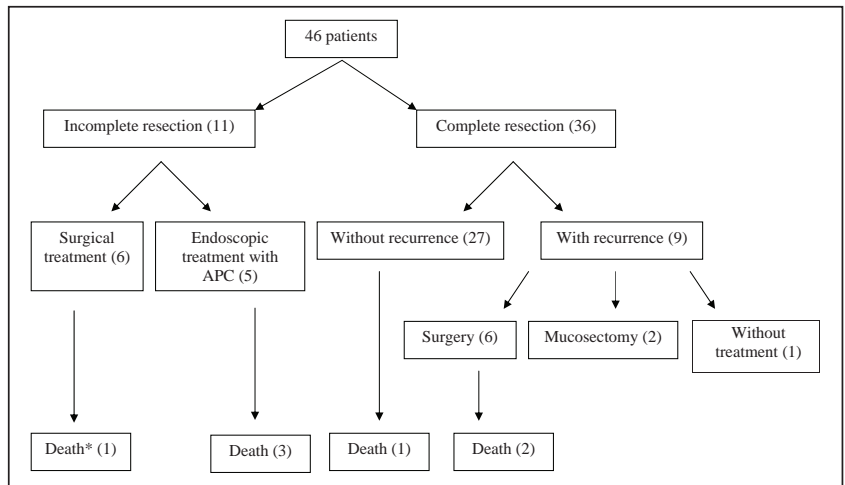

Figure 1) Flow diagram of the clinical evolution of early gastric cancer patients. *With evidence of gastric neoplasms. APC Argon plasma coagulation

one-third of the stomach, a lower rate of complete resection (43\%) was observed. The posterior wall was the location that presented most difficulties for resection (63\%). Conversely, of the six lesions found in the middle one-third of the posterior wall in the stomachs of the incomplete resection group, all lesions were resected successfully. The number of resected fragments was also a predictive factor for incomplete resection $(\mathrm{P}=0.013)$ (Table 3).

Histopathological data, such as histological type and lesion size proved to be predictive factors for incomplete tumour removal (Table 4).

A multivariate analysis revealed that histological type and the number of resected fragments were independent factors for incomplete lesion resection (ie, when the histological type of the cancer was undifferentiated, incomplete resection of the lesion was more likely to occur [OR 0.18; 95\% CI 0.036 to 0.897]). Similarly, in piecemeal resections, the risk of incomplete resection was approximately sevenfold higher (OR 7.34; $95 \%$ CI 1.266 to 42.629 ).

The mean age of the incomplete resection group was $67.6 \pm 22.0$ years (range 21 to 88 years) and five patients (45.4\%) were women. Regarding histological type, two patients had differentiated adenocarcinoma (18.1\%), with a mean lesion size of $2 \pm 1.01 \mathrm{~cm}$ (range $0.5 \mathrm{~cm}$ to $4.5 \mathrm{~cm}$ ). Mucosal invasion was observed in seven cases (63.6\%) and submucosal invasion in the remaining cases. Lesion macroscopic type was classified as IIa in seven $(63.6 \%)$ cases, type IIc in one $(9 \%)$ and type IIa+IIc in three cases $(27.3 \%)$. For all lesions, the
TABLE 2

Demographic data comparison between complete and incomplete resection groups

\begin{tabular}{lccc}
\hline \multirow{2}{*}{ Demographic } & \multicolumn{2}{c}{ Resection } & P \\
\cline { 2 - 3 } Women & Complete & Incomplete & 0.792 \\
Men & $18(50)$ & $5(45.4)$ & \\
Age, years & $18(50)$ & $6(54.6)$ & \\
$<60$ & & & \\
$\geq 60$ & $7(19.4)$ & $3(27.3)$ & \\
Race & $29(81.6)$ & $8(72.7)$ & \\
Caucasian & & & \\
Black & $25(71.5)$ & $9(81.8)$ & 0.250 \\
Asian & $2(5.7)$ & $2(18.2)$ & \\
\hline
\end{tabular}

Data presented as $n$ (\%) unless indicated otherwise

TABLE 3

Endoscopic data comparison between complete and incomplete resection groups

\begin{tabular}{lccc}
\hline & \multicolumn{2}{c}{ Resection } & P \\
\cline { 2 - 3 } Endoscopy factor & Complete & Incomplete & 0.183 \\
Technique & $7(19.4)$ & 0 & \\
Cap & $27(75)$ & $11(100)$ & \\
Strip biopsy & $2(5.6)$ & 0 & 0.660 \\
Insulation-tipped & & & \\
$\quad$ diathermic knife & & & \\
Macroscopic lesion type & $24(66.6)$ & $7(63.7)$ & \\
Ila & $6(16.7)$ & $1(9)$ & \\
Ilc & $6(16.7)$ & $3(27.3)$ & \\
Ila+llc & & $2(18)$ & \\
Number of resected fragments & $22(61.1)$ & $9(82)$ & \\
One & $14(38.9)$ & & \\
Two or more & & & \\
\hline
\end{tabular}

Data presented as $n$ (\%) unless indicated otherwise

TABLE 4

Histopathology data comparison between complete and incomplete resection groups

\begin{tabular}{lccc}
\hline & \multicolumn{2}{c}{ Resection } & P \\
\cline { 2 - 3 } Histopathology factor & Complete & Incomplete & 0.021 \\
Histological cancer type & $12(33.3)$ & $8(72.7)$ & \\
Undifferentiated & $24(66.7)$ & $3(27.3)$ & \\
Differentiated & & & 0.022 \\
Lesion size & $33(91.7)$ & $7(63.6)$ & \\
$\leq 2 \mathrm{~cm}$ & $3(8.3)$ & $4(36.4)$ & \\
$>2$ cm & & & 0.461 \\
Level of invasion & $27(75)$ & $7(63.6)$ & \\
Mucosal & $9(25)$ & $4(36.4)$ & \\
Submucosal & & & \\
\hline
\end{tabular}

Data presented as $n$ (\%) unless indicated otherwise

strip-biospy endoscopic technique was used with a mean of $2.63 \pm 1.36$ fragments (range one to five fragments). The mean follow-up period lasted $67.63 \pm 21.97$ months (range six to 100 months) and six patients were referred for gastrectomy. One of these patients died six months after the procedure. The remaining patients underwent complementary argon plasma coagulation and three of them died; no death was related to 
TABLE 5

Characteristics of patients with incomplete resection

\begin{tabular}{|c|c|c|c|c|c|c|c|}
\hline Patient & $\begin{array}{l}\text { Age, } \\
\text { years }\end{array}$ & Sex & $\begin{array}{l}\text { Histological type } \\
\text { of cancer }\end{array}$ & Lesion size, $\mathrm{cm}$ & Follow-up, months & Procedure & Death \\
\hline 1 & 65 & Female & Undifferentiated & 4.5 & 56 & Gastrectomy & No \\
\hline 2 & 79 & Male & Differentiated & 2.3 & 64 & Gastrectomy & No \\
\hline 3 & 84 & Female & Undifferentiated & 2.0 & 58 & Gastrectomy & No \\
\hline 4 & 88 & Male & Undifferentiated & 0.5 & 6 & Gastrectomy & Yes \\
\hline 5 & 86 & Female & Undifferentiated & 1.5 & 95 & Gastrectomy & No \\
\hline 6 & 86 & Female & Undifferentiated & 1.9 & 24 & Argon plasma coagulation & Yes \\
\hline 7 & 40 & Female & Undifferentiated & 1.3 & 110 & Gastrectomy & No \\
\hline 8 & 77 & Male & Undifferentiated & 1.5 & 28 & Argon plasma coagulation & Yes \\
\hline 9 & 50 & Male & Undifferentiated & 2.5 & 36 & Argon plasma coagulation & Yes \\
\hline 10 & 68 & Male & Undifferentiated & 1.5 & 78 & Argon plasma coagulation & No \\
\hline 11 & 21 & Male & Differentiated & 2.5 & 43 & Argon plasma coagulation & No \\
\hline
\end{tabular}

TABLE 6

Comparison of the number of resected fragments with lesion size in the incomplete resection group

\begin{tabular}{llll}
\hline & \multicolumn{2}{c}{ Number of resected fragments } & \\
\cline { 2 - 3 } & \multicolumn{1}{c}{ One } & Two or more & P \\
\hline Lesion size & & & 0.887 \\
$\leq 2 \mathrm{~cm}$ & $1(16.7)$ & $5(83.3)$ & \\
$>2 \mathrm{~cm}$ & $1(20)$ & $5(80)$ & \\
\hline
\end{tabular}

Data presented as $n$ (\%) unless indicated otherwise

gastric cancer. All of these patients had histologically defined undifferentiated lesions (Table 5).

No statistical difference was observed between the number of resected fragments and lesion size in the incomplete resection group (Table 6). The same was observed between the number of fragments and their location $(\mathrm{P}=0.202)$.

In the analysis of factors which included age, follow-up period, number of resected fragments and lesion size (as continuous numeric parameters), only the number of fragments and lesion size were found to be predictive factors for incomplete resection.

The mean age of the complete resection group was $69.4 \pm 11.1$ years (range 42 to 102 years) and 18 patients $(51.4 \%)$ were women. Well-differentiated adenocarcinomas were present in 24 patients $(66.6 \%)$, with a mean lesion size of $1.35 \pm 0.54 \mathrm{~cm}$ (range $0.6 \mathrm{~cm}$ to $2.7 \mathrm{~cm}$ ). Mucosal invasion was observed in 27 cases (75\%) and submucosal invasion in the remaining cases. Macroscopic type Ila lesions were found in 24 $(66.6 \%)$ cases, and type IIc and type IIa+IIc in six cases each $(16.7 \%)$, respectively. The mucosectomy technique applied was stratified into cap for seven cases (19.4\%), strip biopsy for $27(75 \%)$ and IT knife for two cases (5.6\%). The mean number of resected fragments was $1.83 \pm 1.4$ (range one to five). The mean length of the follow-up period for this group was $70.0 \pm 38.0$ months (range six to 136 months).

In this group, larger lesion size was observed to be associated with a higher number of resected fragments $(\mathrm{P}=0.018)$. However, no statistical difference was found between the number of fragments or the lesion location and the endoscopic technique used. The same was observed for the endoscopic technique applied and lesion size (Table 7).

In the complete resection group, patients were divided into subgroups of patients with and without recurrence. Local
TABLE 7

Comparison between the number of fragments with endoscopic technique applied and lesion size in the complete resection group

\begin{tabular}{lccc}
\hline & \multicolumn{2}{c}{ Number of fragments } & \\
\cline { 2 - 3 } & One & Two or more & P \\
\hline Technique & & & \\
$\quad$ Cap & $4(57.1)$ & $3(42.9)$ & 0.507 \\
$\quad \begin{array}{l}\text { Strip biopsy } \\
\quad \text { Insulation-tipped }\end{array} \quad 2(59.3)$ & $11(40.7)$ & \\
$\quad$ diathermic knife & $2(100)$ & 0 & \\
Lesion size & & & \\
$\leq 2 \mathrm{~cm}$ & $20(71.4)$ & $8(28.6)$ & 0.018 \\
$>2 \mathrm{~cm}$ & $2(25)$ & $6(75)$ & \\
\hline
\end{tabular}

Data presented as $n(\%)$ unless indicated otherwise

recurrence occurred within a mean of $3.5 \pm 2.12$ months (range one to three months) in nine cases (25\%).

In the comparison between the subgroups with and without recurrence, demographic data were not found to be predictive factors for local recurrence.

A significant difference in EGC recurrence with regard to the technique used for EMR was demonstrated using the cap (suck and cut) technique in five cases of recurrence (55.5\%; $\mathrm{P}=0.006$ ). In the subgroup without recurrence, this technique was performed in only two cases $(7.4 \%)$ (Table 8 ).

Of the nine cases with submucosal invasion, there were three local recurrences $(33.3 \%)$. However, in the mucosal invasion subgroup, there were six recurrence cases (66.7\%), of which five were of the well-differentiated histological type (ie, they presented high likelihood of cure).

The mean follow-up period for the subgroup without recurrence was $68.1 \pm 34.9$ months and for the recurrence group, $74.7 \pm 47.7$ months $(\mathrm{P}=0.707)$.

In the multivariate analysis of factors used in the comparison between subgroups with and without recurrence, no variable correlating with local recurrence was found to be statistically significant.

\section{DISCUSSION}

Despite the reduction in gastric cancer incidence in the past 60 years, it remains the fourth most common cause of malignant neoplasm worldwide. Approximately 600,000 new cases are diagnosed every year. Almost two-thirds of these individuals will die from the disease (13). 
The cure rate for advanced gastric cancer has remained unchanged for the past 40 years and the five-year survival rate has not surpassed the mean value of $15 \%$ (14). In Japan, the mean five-year survival rate of patients with early lesions treated in this stage is greater than $90 \%(15,16)$, demonstrating the importance of detecting neoplasm in its initial phase.

Lymph node metastasis is the most influencial factor in the survival of a patient with EGC (17-21). Gastric neoplasm with an invasion depth restricted to the mucosal layer, without ulcer or scar, demonstrates lymph node involvement in approximately $1 \%$ to $3 \%$ of cases. When there is submucosal invasion, lymph node involvement is approximately $11 \%$ to $20 \%$ (16,21-29). Findings of lymphatic emboli, ulceration and tumours larger than $3 \mathrm{~cm}$ in size have been revealed as independent factors for lymph node involvement. In their absence, a malignant lymph node involvement risk of $0.23 \%$ was observed (22).

Because lymph node involvement in gastric cancer restricted to the mucosa and submucosa is unlikely, endoscopic treatment by local resection, widely known as mucosectomy, was proposed in earlier reports $(8,30)$. EGC endoscopic resection was found to be similar in efficacy to surgical resection, as well as minimally invasive and inexpensive to perform (31).

Generally accepted indications for EMR related to EGC observed in the present study, are (8,32-38):

- Differentiated adenocarcinoma;

- Elevated type of cancer not exceeding $20 \mathrm{~mm}$ in size; and

- Flat type or depressed types of cancer without ulceration and not exceeding $10 \mathrm{~mm}$ in size.

With these criteria, cases with lymph node metastases or submucosal invasion were excluded $(3,39)$. Nonetheless, complete resection rates by EMR are lower than by surgical resection (40). Complete resection rates ranging from $53.8 \%$ to $91.3 \%$ for EMR are reported, whereas they reach $100 \%$ for surgical resection $(32-38,41)$. In the present study, the complete resection rate was found to be $76.6 \%$ by endoscopy with local recurrence occuring at a rate of $25 \%$ among these patients. In the literature, local recurrence after EMR is reported to range from $2 \%$ to $35 \%$ (5).

Regarding factors for local recurrence, piecemeal resection has been brought to attention (40). In the study conducted by Miyata et al (40), larger lesion size was found to be associated with a higher number of resected fragments. Other studies demonstrated that the larger the size of the lesion, the lower the rate of en bloc resection, even with different techniques, but with adjacent local recurrence rates of $1.7 \%$ and $2.3 \%$, respectively $(5,42)$. In the present study, the majority of lesions $(72.3 \%)$ were smaller than $2 \mathrm{~cm}$ in size, of which 23 of $34(67.6 \%)$ were resected en bloc and the overall en bloc resection rate was $51 \%$. Similar to the above mentioned studies, the larger the lesion, the higher the probability of en bloc resection. In fact, piecemeal resection was found to be an independent factor for the finding of incomplete neoplasm resection. The other independent factor for this finding was an undifferentiated histological type, probably due to its infiltrating growth and nonexpanding character, which hinders the exact determination of resection margins. Indication for endoscopic treatment resulted from the initial refusal of conventional surgical treatment.

\section{TABLE 8}

Endoscopic data comparison between subgroups with and without early gastric cancer recurrence

\begin{tabular}{llcc}
\hline Endoscopy factor & Recurrence & No recurrence & P \\
\hline Technique & & & 0.006 \\
Cap & $5(55.5)$ & $2(7.4)$ & \\
Strip biopsy & $4(44.5)$ & $23(85.2)$ & \\
Insulation-tipped & 0 & $2(7.4)$ & \\
$\quad$ diathermic knife & & & 0.295 \\
Macroscopic lesion type & & $19(70.3)$ & \\
Ila & $5(55.5)$ & $5(18.5)$ & \\
IIc & $1(11.2)$ & $3(11.2)$ & \\
Ila+Ilc & $3(33.3)$ & & 0.643 \\
Number of resection & & & \\
fragments & & $17(62.9)$ & \\
$\quad$ One & $5(55.5)$ & $10(37.1)$ & \\
Two or more & $4(44.5)$ & & \\
\hline
\end{tabular}

Data presented as $n$ (\%) unless indicated otherwise

New accessories, such as the IT knife $(43,44)$ and the development of a new mucosectomy technique known as endoscopic submucosal dissection (ESD) (45), were made possible by technological advances. With the ESD technique, en bloc resection rates were $98 \%$ to $100 \%$ for lesions smaller than $2 \mathrm{~cm}$ in size $(44-46)$ and $79 \%$ to $97 \%$ for lesions larger than $2 \mathrm{~cm}$ $(5,46-49)$, with local recurrence rates from $0 \%$ to $1 \%(5,47)$, justifying its widespread adoption. In the present study, only $4 \%$ of patients underwent mucosectomy by ESD because ESD is a more recently developed, complex technique.

Cases of differentiated-type carcinomas with pronounced invasion and metastases are noted at times, even in the early stage (28), expressing in situations in which histogenesis and biological behavior are not compatible with the differentiated versus undifferentiated type classifications (49-51). In these cases, endoscopic resection is hindered by the likelihood of local recurrence or metastasis. In the present study, patients with differentiated-type intramucosal gastric cancer, resected by gastric mucosectomy with tumour-free margins without lymphatic or venous involvement, actually presented with a recurrence rate of $22.7 \%$, whereas in the literature these figures range from $2.8 \%$ to $5.7 \%$. To explain this unexpected discrepancy, immunohistochemical evaluations have emerged, such as the determination of p53, $\mathrm{Ki}-67$ and mucin (MUC) expression levels. Shibata et al (52) used the mucins MUC2, human gastric mucin (HGM) and CD10 to classify 50 cases of differentiated EGC. In this study, the ratio of apoptosis to proliferation rate was calculated and the lack of expression of the mucins MUC2 and CD10 - typical of intestinal epithelium - correlated with lower apoptosis rates and higher proliferation rates, comparable with rates found for undifferentiated tumours.

Other authors (53) have reinforced the idea of using CD10, MUC2, HGM and concanavalin A for detecting the most aggressive phenotype (gastric type) of intramucosal differentiated tumours in $36.8 \%$ (42 of 114) of cases. These studies generated the hypothesis that the immunohistochemical profile of HGM expression could be a prognostic factor after early endoscopic resection of intramucosal differentiated EGC, and may finally explain the aggressive and unexpected behaviour 
that some resected lesions presented in this series of cases. The immunohistochemical profile of these lesions are currently being investigated.

\section{CONCLUSION}

EGC endoscopic piecemeal resection and an undifferentiated histological type are independent risk factors for higher risk of incomplete resection. EMR with the cap technique is related to a higher probability of local recurrence of gastric cancer due to the size limitation imposed by the technique used for resection. Finally, for patients who fit the criteria of cure with endoscopic resection, the biological behavior of gastric lesions may be unexpectedly aggressive, demanding the search for other prognostic factors other than lesion size, level of submucosal invasion or its location.

\section{REFERENCES}

1. Onodera H, Tokunaga A, Yoshiyuji T, et al. Surgical outcome of 483 patients with early gastric cancer: Prognosis, postoperative morbidity and mortality, and gastric remnant cancer. Hepatogastroenterology 2004;51:82-5.

2. Cohen MM, Zoeter A, Loar C. Survival following surgical treatment of gastric cancer: A challenge for the community endoscopist. Surg Endosc 1994;8:862-6.

3. Sano T, Kobori O, Muto T. Lymph node metastasis from early gastric cancer: Endoscopic resection of tumour. Br J Surg 1992;79:241-4.

4. Tanabe S, Koizumi W, Mitomi H, et al. Clinical outcome of endoscopic aspiration mucosectomy for early stage gastric cancer. Gastrointest Endosc 2002;56:708-13.

5. Gotoda T, Yamamoto H, Soetikno RM. Endoscopic submucosal dissection of early gastric cancer. J Gastroenterol 2006;41:929-42.

6. Tada M, Yanai H, Takemoto T. New technique of gastric biopsy. Stomach Intest 1984:19:1107.

7. Mitsunaga A. Difference between mucosal and submucosal gastric cancer on endoscopic diagnosis. Stomach Intest 1992;27:1151-66.

8. Tada M, Murakami A, Karita M, Yanai H, Okita K. Endoscopic resection of early gastric cancer. Endoscopy 1993;25:445-50.

9. Kojima T, Parra-Blanco A, Takahashi H, Fujita R. Outcome of endoscopic mucosal resection of early gastric cancer: Review of the Japanese literature. Gastrointest Endosc 1998;48:550-5.

10. Maluf-Filho F, Sakai P, Gama-Rodrigues J, et al. Endoscopic treatment of early gastric cancer: A Brazilian experience. In: Kim JP, Min JS, Mok YJ, eds. Proceedings of the 3rd International Gastric Cancer Congress, Seoul 1999. Bologna: Monduzzi Ed,1999:449-55.

11. Nishi M, Ishihara S, Nakajima T, et al. Chronological changes of characteristics of early gastric cancer and therapy: Experience in the Cancer Institute Hospital of Tokyo, 1950-1994. J Cancer Res Clin Oncol 1995;121:535-41.

12. Japanese Gastric Cancer Association. Japanese Classification of Gastric Carcinoma. 2nd English Edition. Gastric Cancer 1998;1:10-24.

13. Ferlay J, Bray F, Pisani P, Parkin DM. GLOBOCAN 2002: Cancer Incidence, Mortality and Prevalence Worldwide. Lyon: IARC Press, 2004.

14. Muir CS, Harvey JC. Cancer of the stomach. GI Cancer 1995;1:213-25.

15. Yamazaki H, Oshima A, Murakami R, Endoh S, Ubukata T. A longterm follow-up study of patients with gastric cancer detected by mass screening. Cancer 1989;63:613-7.

16. Sue-Ling HM, Johnston D, Martin IG, et al. Gastric cancer: A curable disease in Britain. BMJ 1993;307:591-6.

17. Maehara Y, Okuyama T, Oshiro T, et al. Early carcinoma of the stomach. Surg Gynecol Obstet 1993;177:593-7.

18. Kim JP, Hur YS, Yang HK. Lymph node metastasis as a significant prognostic factor in early gastric cancer: Analysis of 1,136 early gastric cancers. Ann Surg Oncol 1995;2:308-13.

19. Miwa K, Miyazaki I, Sahara H, et al. Rationale for extensive lymphadenectomy in early gastric carcinoma. Br J Cancer 1995;72:1518-24.

20. Isozaki H, Tanaka N, Okajima K. General and specific prognostic factors of early gastric carcinoma treated with curative surgery. Hepatogastroenterology 1999;46:1800-8.
21. Kunisaki C, Shimada H, Takahashi M, et al. Prognostic factors in early gastric cancer. Hepatogastroenterology 2001;48:294-8.

22. Yamao T, Shirao K, Ono H, et al. Risk factors for lymph node metastasis from intramucosal gastric carcinoma. Cancer 1996;77:602-6.

23. Koufuji K, Takeda J, Toyonaga A, et al. Early gastric cancer and lymph node metastasis. Kurume Med J 1997;44:157-64.

24. Kurihara N, Kubota T, Otani Y, et al. Lymph node metastasis of early gastric cancer with submucosal invasion. Br J Surg 1998;85:835-9.

25. Namieno T, Koito K, Higashi T, Takahashi M, Yamashita K, Kondo Y. Assessing the suitability of gastric carcinoma for limited resection: Endoscopic prediction of lymph node metastases. World J Surg 1998;22:859-64.

26. Nakamura K, Morisaki T, Sugitani A, et al. An early gastric carcinoma treatment strategy based on analysis of lymph node metastasis. Cancer 1999;85:1500-5.

27. Yasuda K, Shiraishi N, Suematsu T, Yamaguchi K, Adachi Y, Kitano S. Rate of detection of lymph node metastasis is correlated with the depth of submucosal invasion in early stage gastric carcinoma. Cancer 1999;85:2119-23.

28. Gotoda T, Yanagisawa A, Sasako M, et al. Incidence of lymph node metastasis from early gastric cancer: Estimation with a large number of cases at two large centers. Gastric Cancer 2000;3:219-25.

29. Yamada H, Nihei Z, Yamashita T, Shirota Y, Ichikawa W, Sugihara K. Is lymphadenectomy needed for all submucosal gastric cancers? Eur J Surg 2001;167:199-203.

30. Deyhle P, Largiader F, Jenny S. A method for endoscopic electroresection of sessile colonic polyps. Endoscopy 1973;5:38-40.

31. Ludwig K, Klautke G, Bernhard J, Weiner R. Minimally invasive and local treatment for mucosal early gastric cancer. Surg Endosc 2005;19:1362-6.

32. Fujino M, Morozumi A, Kojima Y, et al. Gastric carcinoma, an endoscopically curable disease. Bildgebung 1994;61:38-40.

33. Takekoshi T, Baba Y, Ota H, et al. Endoscopic resection of early gastric carcinoma: Results of a retrospective analysis of 308 cases. Endoscopy 1994;26:352-8.

34. Hiki Y, Shimano H, Mieno H, Sakakibara Y, Kobayashi N, Saigenji K. Modified treatment of early gastric cancer: Evaluation of endoscopic treatment of early gastric cancers with respect to treatment indication groups. World J Surg 1995;19:517-22.

35. Hamada T, Kondo K. Endoscopic mucosal resection for early gastric cancer. Int Med 1997;36:131.

36. Korenaga D, Orita H, Maekawa A, et al. Pathological appearance of stomach after endoscopic mucosal resection for early gastric cancer. Br J Surg 1997;84:1563-6.

37. Noda M, Kodama T, Atsumi M, et al. Possibilities and limitations of endoscopic resection for early gastric cancer. Endoscopy 1997;29:361-5.

38. Hiraga Y, Tanaka S, Haruma K. Follow-up study on local residual recurrence and prognosis of early gastric cancers resected endoscopically. (in Japanese, with English figure, legends, table and summary) Gastroenterol Endosc 1998;40:2102-12.

39. Ohta H, Noguchi Y, Takagi K, Nishi M, Kajitani T, Kato Y. Early gastric carcinoma with special reference to macroscopic classification. Cancer 1987;60:1099-106.

40. Miyata M, Yokoyama Y, Okoyama N, et al. What are the appropriate indications for endoscopic mucosal resection for early gastric cancer? Analysis of 256 endoscopically resected lesions. Endoscopy 2000;32:773-8.

41. Yoshida S. Endoscopic diagnosis and treatment of early cancer in the alimentary tract. Digestion 1998;59:502-8.

42. Takeshita K, Tani M, Inoue H, et al. A new method of endoscope mucosal resection of neoplastic lesions in the stomach: Its technical features and results. Hepatogastroenterology 1997;44:1602-11.

43. Hosokawa K, Yoshida S. Recent advances in endoscopic mucosal resection of early gastric cancer. Jpn J Cancer Chemother 1998:25;483.

44. Gotoda T, Kondo H, Ono H, et al. A new endoscopic mucosal resection procedure using an insulation-tipped electrosurgical knife for rectal flat lesions: A report of two cases. Gastrointest Endosc 1999;50:560-3.

45. Ono H, Kondo H, Gotoda T, et al. Endoscopic mucosal resection for treatment of early gastric cancer. Gut 2001;48:225-9.

46. Oyama T, Kikuchi Y. Aggressive endoscopic mucosal resection in the upper GI tract - hook knife EMR method. Minim Invasive Ther Allied Technol 2002;11:291-5. 
47. Yamamoto H, Kawata H, Sunada K, et al. Successful en bloc resection of large superficial tumors in the stomach and colon using sodium hyaluronate and small-caliber-tip transparent hood. Endoscopy 2003;25:690-4.

48. Hamanaka H, Gotoda T. Endoscopic resection for early gastric cancer and future expectations. Dig Endosc 2005;17:275-85.

49. Nakamura K, Sugano H, Takagi K. Carcinoma of the stomach in incipient phase: Its histogenesis and histological appearances. Jpn J Cancer Res 1968;59:251-8.

50. Nagayo T. Microscopical cancer of the stomach: A study on histogenesis of gastric carcinoma. Int J Cancer 1975;16:52-60.
51. Nakamura K. Special features of intestinal metaplasia and its relation to early gastric carcinoma in man: Observation by a method in which leucine aminopeptidase activity is used. J Natl Cancer Inst 1978;61:693-702.

52. Shibata N, Watari J, Fujiya M, Tanno S, Saitoh Y, Kohgo Y. Cell kinetics and genetic instabilities in differentiated type early gastric cancers with different mucin phenotype. Hum Pathol 2003;34:32-40.

53. Kabashima A, Yao T, Sugimachi K, Tsuneyoshi M. Relationship between biologic behavior and phenotypic expression in intramucosal gastric carcinomas. Hum Pathol 2002;33:80-6. 


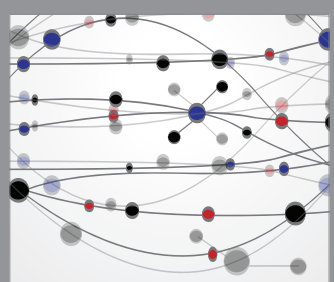

The Scientific World Journal
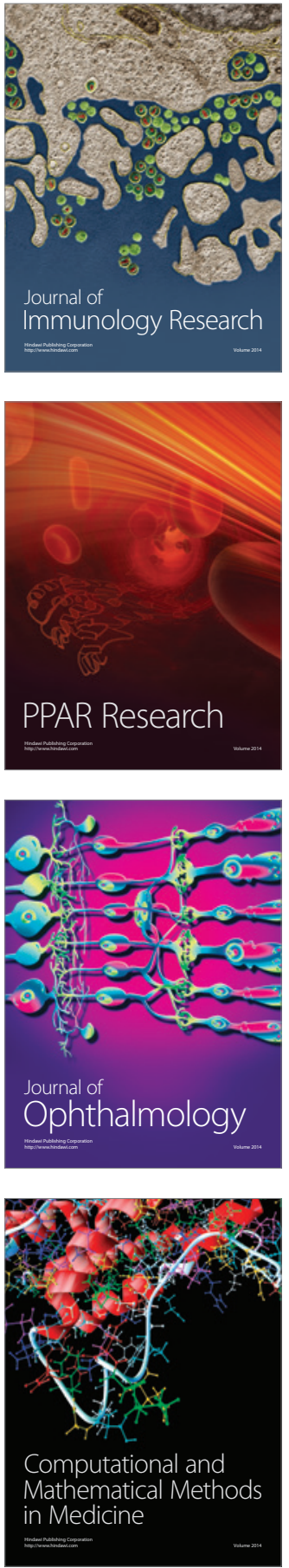

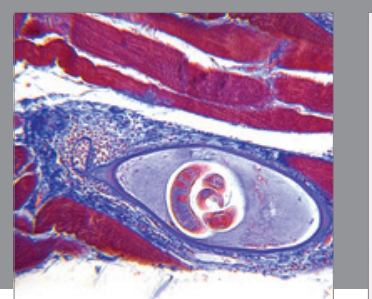

Gastroenterology Research and Practice

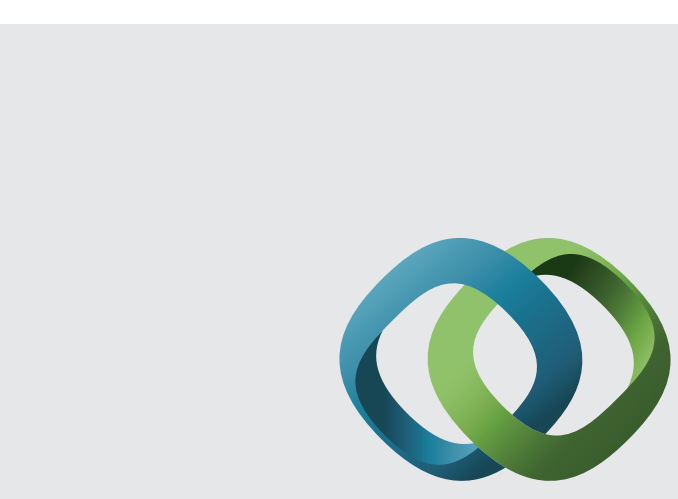

\section{Hindawi}

Submit your manuscripts at

http://www.hindawi.com
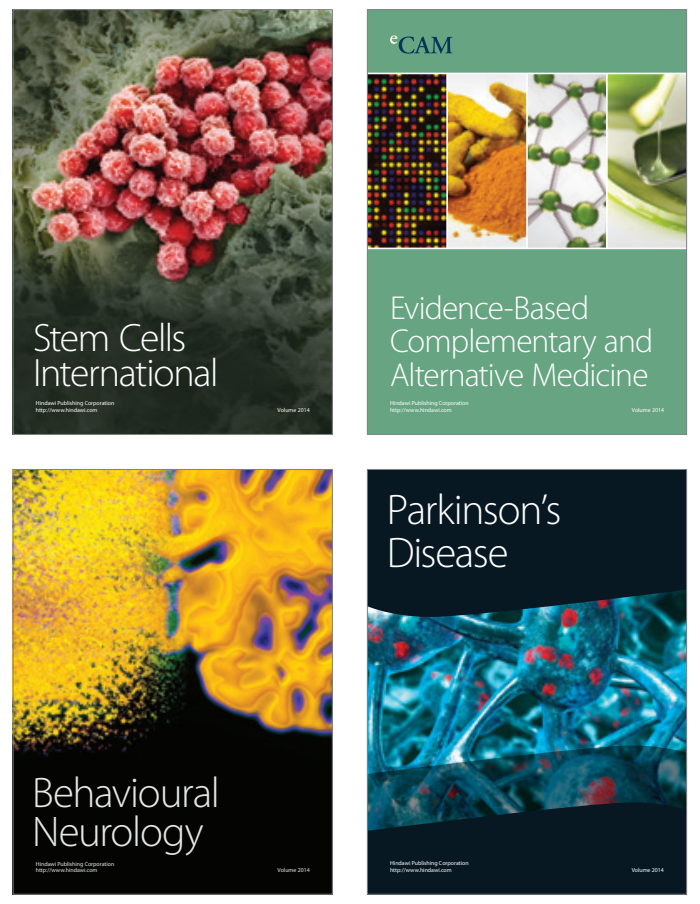
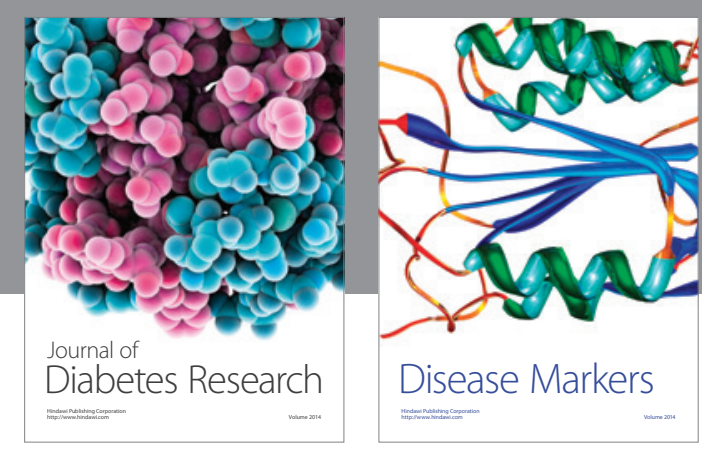

Disease Markers
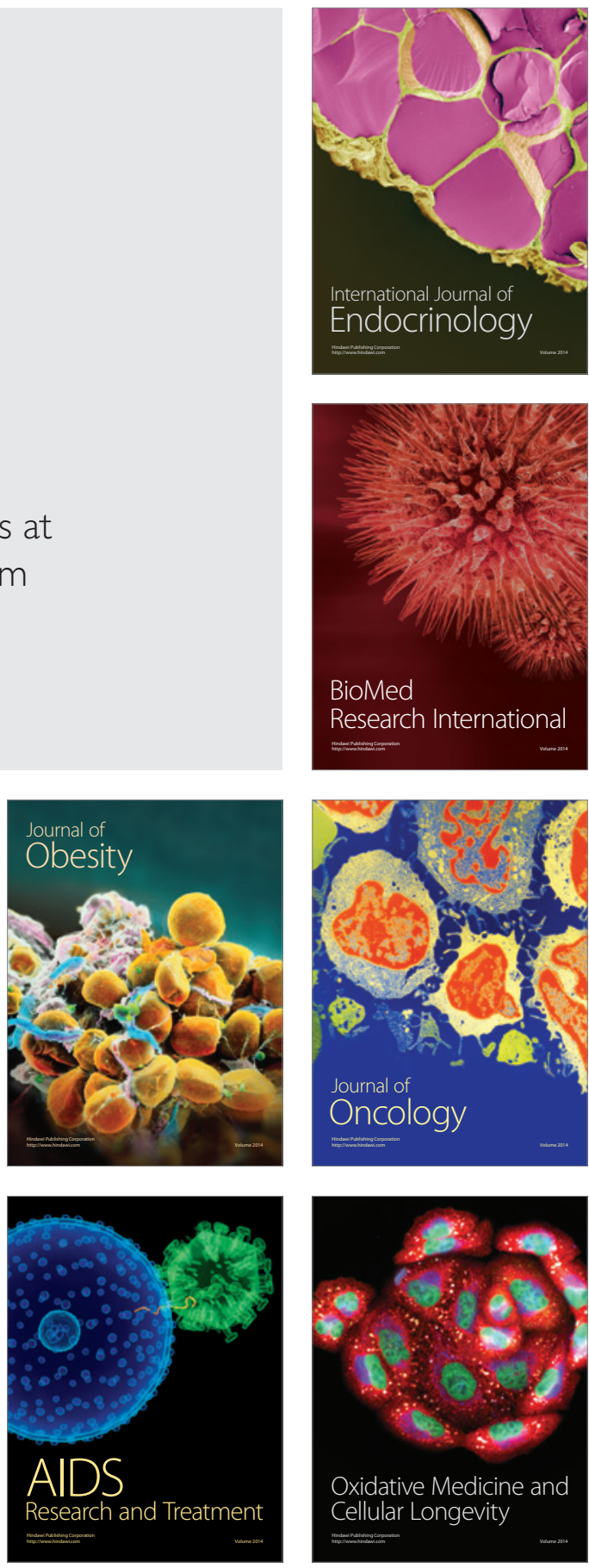